\title{
INABILITIES, EXCUSES AND EXEMPTIONS
}

\section{INCAPACIDADES, JUSTIFICATIVAS E ISENÇÕES}

\author{
DAVID BOTTING \\ (Universidade Nova de Lisboa, Portugal)
}

\begin{abstract}
In this paper I will argue, following Moody-Adams's (1994) paper "Culture, responsibility and affected ignorance," that inability does not excuse in general, but against Moody-Adams I will argue that this is not because of "affected ignorance" but simply because of responsibilities individual agents have by virtue of belonging to and participating in the collective actions of a certain kind of collective. Excusability has been misdiagnosed as depending on whether the ignorance of wrongdoing involved is culpable or non-culpable.

Keywords: The inability thesis. Reactive attitudes. Collective responsibility. Collective intentionality
\end{abstract}

\section{The Terms of the Problem}

\section{Inability}

Inability, as it will be discussed in this paper, is given a specific meaning expressed in the Inability Thesis: sometimes agents are not responsible for their wrongdoing in cases where their culture approves of that wrongdoing or the wrongdoing is part of that culture's accepted practices. Typical examples are abuses of minorities (or in some cases majorities), such as the Greek treatment of slaves or the racial segregation policies of the American South, the Nazis, and apartheid.

The Inability Thesis is usually defended on the grounds that being raised within this culture - being exposed to these cultural influences and to social pressures to conform to the institutions and practices of this culture - excuses the wrongdoer because it makes them unable to see the moral wrongness of their acts. In these cultures, these acts are approved of, are examples of an accepted cultural practice and are thereby expressions of a value-system that those raised in the culture may never question; furthermore, being raised in this culture is an accident of circumstance that the agent has no control over. Thus, the inability is identified with moral ignorance, and the relevant question is then whether this ignorance is culpable or non-culpable. Is the Greek slave-owner morally responsible for the mistreatment of his slaves? Is it the culture itself that is responsible? Both? Neither?

Is the Greek slave-owner culpable for failing to recognize the moral wrongness of his acts? Those who support the Inability Thesis claim that the moral ignorance is non-culpable, at least in some cases. Moody-Adams rejects the Inability Thesis: a person can reasonably be 
expected to inquire into the morality of their acts by, e.g., looking for evidence; the fact that they do not do so and accept their cultural limitations does not make their ignorance nonculpable but only what she calls "affected ignorance." The Greek slave-owner is morally responsible for his possession of and treatment of slaves and his ignorance that this is wrong is the "affected ignorance" of the one who benefits from the cultural practice in question. The moral knowledge is available to reflection, she seems to say, and whether or not the culture rewards or provides motivation for this reflection is not the point. To make the culture responsible but not the individual agent lets the agent off too easily and counts the culture as an agent in itself, whereas the culture only acts by virtue of individual agents acting, and only expresses values by virtue of individual agents perpetuating those values (Moody-Adams, 1994, 295-96). Since it is not an agent and does not cause anything independently of the behaviour of its members, a culture cannot literally incapacitate anyone from the kind of moral reflection and recognition Moody-Adams says should take place. This does not mean failing to acknowledge how hard it is or would have been to be moral in these cultures, or failing to show compassion and even forgiveness - our responses may be mitigated by a perceived lack of the agent's moral education. But not to hold them responsible amounts to denying their humanity (Moody-Adams, 1994, 305-306).

Later, I will argue that where some kind of collective intentionality is involved, such as participating in a social practice (even where such participation is minimal, such as passive acceptance of the practice), the importance of the moral knowledge of the individual agent is severely diminished. I will put the point this way: the slave-owner who believes that slavery is a morally wrong practice but who practices it anyway is neither more nor less to blame for his practicing slavery than the slave-owner who is literally morally blind and does not recognize there to be a moral case to answer. In fact - though I will not argue for it - the refusal to "affect" ignorance in the first case may even be in some sense commendable (as, e.g., a refusal to compound one's moral defects with "bad faith"), without making the agent any less responsible for the original wrongdoing. We can account for this different tone to our resentment by noting that affected ignorance and other avoidable epistemic failures amount to wrongdoing in and of themselves; it is not that we are responsible for the original wrongdoing when the ignorance is culpable and excused when the ignorance is non-culpable. In other words, it is not the relevance of moral knowledge to our moral evaluation of the agent that I deny, but only its relevance to our attribution of responsibility to the agent for the kinds of acts under discussion. We cannot go in the kind of way that all participants in the discussion seem to suppose from "He is culpable for being morally ignorant of the moral wrongness of 
slavery" and from blaming the slave-owner for this ignorance, to "He is morally responsible for owning slaves" and blaming him for this, or conversely from "He is non-culpable for being morally ignorant of the moral wrongness of slavery" and from not blaming him for this ignorance, to "He is not morally responsible for owning slaves" and not blaming him for this. We must guard ourselves from confusing our blaming the epistemic failure from blaming the act; blame for the epistemic failure and blame for the act are logically independent. This will amount to arguing that there are different epistemic conditions on the agent for this kind of collective wrongdoing than for individual wrongdoing, since it is usually held that for individual wrongdoing must be aware of what he is doing and be doing it intentionally. The discussion in the literature so far, however, has focussed on the question of whether moral ignorance is non-culpable, so this is where we must start.

In a reply to Moody-Adams' paper, Benson (2001) basically accuses Moody-Adams of attacking a straw man. It is not a question, he says, of an agent's being literally incapable or incapacitated by their cultural upbringing of engaging in the kind of moral reflection by which he agrees that the moral wrongness of their acts should be manifest. This is an overly literal and unnecessarily strict interpretation of the "inability" referred to. It is also not a question of the culture literally causing the behaviour of its members, which he agrees with MoodyAdams that it does not. Rather, Benson $(2001,613)$ says that the relevant question is whether cultural influences could affect his agency in such a manner that it would be unreasonable or unfair for others to hold him to the expectation that he reflectively scrutinize the ethics of slavery. For this is what his responsibility for his ignorance would consist in: if he were responsible, it would be appropriate for others to hold him to the moral demand that he form certain judgments. Whether we think that cultural influences render him strictly incapable of knowing that slavery is wrong, surely it would be unreasonable to hold him to the expectation that he should know this.

This still treats the slave-owner as a person, even though we do not hold him responsible. It is left open whether the culture itself could be held responsible. Cultural influences need not play a causal role here, but only an explanatory role in the explanation of behaviour, and Benson $(2001,616)$ notes that Moody-Adams allows cultural influences to play this role. Benson's conclusion is that some moral ignorance is affected but some is not. For instance, some of the slaves themselves may have so internalized the cultural practice that they are morally ignorant of its moral wrongness, yet clearly they are not the ones who benefit from the practice; the evidence of moral wrongness is not as freely available as Moody- 
Adams supposes, either for slave-owner or slave (Benson, 2001, 611-13).

In another critique, Isaacs (1997) sums up Moody-Adams account by saying that according to Moody-Adams's idea of affected ignorance, inability does not mitigate. Cultures are not agents or forces, so if we are to blame anyone (and it seems to be assumed here that we must) then we must blame individuals while still recognizing how difficult it might have been for them and modify blame to reflect this. Isaacs denies that every case of moral ignorance is a case of affected ignorance, noting that most of our own moral knowledge is due to cultural influence and the cultural institutions of our moral education and not our own powers of moral perception or rational scrutiny. Isaacs seems to be saying that although the moral wrongness is manifest to us from our viewpoint, it is anachronistic to suppose that it should be equally manifest to members of the culture should they simply take the trouble to look. In some contexts such evidence is available, but in others it is not, or if there is, there is no reason to look for it unless there is already recognized to be either a gap in our moral knowledge or a moral dimension to the cultural practice in question; the problem with moral blindness is that often it is blindness to the fact that there is a moral issue at all, that there is a moral principle at stake (Isaacs, 1997, 672-75). Rather than blame, or even reproach, such wrongdoers, Isaacs $(1997,679-81)$ suggests we should open a dialogue with them and in this way make the evidence available. Only if they ignore the evidence presented is their ignorance affected and culpable.

For Pleasants also, cultural influences make at least some moral ignorance nonculpable and thereby diminish the responsibility of the agent. Pleasants (2008) seems to follow Isaacs in so far as he denies that moral truths are as manifest and as discoverable by moral reflection as both Moody-Adams and Benson suppose, and re-iterates Benson's point that the "inability" is a matter of what it is "reasonable to expect" and that Moody-Adams's reading of "inability" is implausibly strong. Thus, Pleasants $(2008$, 99) reformulates the Inability Thesis as: "Members may be unable to see an institutionalized practice sustained by their society in the way that its dissident critics advocate, as a morally wrong state of affairs that should be abolished or reformed." It is existing dissidence (here also Pleasants seems to follow Isaacs) that motivates the kind of critical reflection on our practices by which we should eventually become aware of their moral wrongness. It is implied that if there is no existing dissidence then the moral ignorance is non-culpable. But even if there is such dissidence, Pleasants would still say that the moral ignorance may be non-culpable. The ignorance in question may only be recognized to be ignorance when assessed against norms to be found in the moral value-systems of our later (and presumably more enlightened) culture. 
It is unreasonable for $u s$ to be morally ignorant of the moral wrongness of slavery because for us this item of moral knowledge is a fait accompli that we have exerted no effort to acquire beyond, so to speak, paying attention in class. It is not reasonable for us to expect the members of the culture to (be able to) see their practices in the way that we do. If it were, then we should expect members of our own culture who disagree with us over some moral issue to be able to see that we are right, but instead we treat these as serious moral issues rather than as cases of moral blindness, still less of affected ignorance. This is a double-standard - the disagreement between the conservatives and dissidents in a culture should also be treated as a serious moral issue, and it seems to be supposed that we are not to be held responsible for acts whose moral wrongness are the subject of serious disagreement (Pleasants, 2008, 102-104). Reasonable people may disagree without apparently violating any of their moral principles or affecting ignorance; the way to resolve disagreement is to persuade one or the other that they are, in fact, inconsistent in the application of their own principles, to show that the respect the Greeks deem to owe to each other, for example, is due also to other races. Argument by analogy is a preferred method here. This failure that Pleasants $(2008,110)$ calls a failure to "see-as" is non-culpable.

\section{Excuses and exemptions}

Here I will briefly summarize the account of excuses and exemptions as it occurs in Strawson's "Freedom and Resentment."

Excuses function by showing that an action did not manifest ill-will and obtain when the agent could say in response "I didn't mean to," "I hadn't realized," "I didn't know," along with things like "I couldn't help it" when backed by "I was pushed," "I had to do it," "It was the only way," or "They gave me no choice" (Strawson 2008, 7-8). One kind of reason that the norms of appropriateness are sensitive to, then, are those concerned with quality of will. Importantly, an agent excused in this way is still held to expectations and as one for whom reactive attitudes are apt (Strawson, 2008, 7-8).

Exemptions function by showing that the agent's agency is too diminished either by their incapacity to understand expectations and norms, or by their incapacity to regulate themselves by those expectations and norms, for it to be appropriate to hold them to those expectations and norms; they are not apt objects for reactive attitudes. Exemptions obtain when the agent (or someone on the agent's behalf) could say in response "He wasn't himself," 
"He has been under very great strain recently," "He was acting under post-hypnotic suggestion," "He's only a child," "He's a hopeless schizophrenic," "His mind has been systematically perverted," or "That's purely compulsive behaviour on his part." A second kind of reason that the norms of appropriateness are sensitive to, then, are those concerned with incapacity (Strawson, 2008, 8-10). Here the reactive attitudes should be replaced with objective attitudes and by doing so we treat the agent as less than fully human, in some sense, and seek only to manage him.

There are a number of reactive attitudes (and different accounts of what the reactive attitudes are and should be), but principal among them are resentment and indignation. Having one of these reactive attitudes towards an agent amounts to holding that agent responsible, and it is often maintained that an agent is responsible if it is appropriate to hold them responsible. The conditions for being responsible are then discoverable by examining the reasons for which we (appropriately) hold reactive attitudes, cease to hold them, or modify them, rather than by philosophical analysis of the concept of responsibility. This is what qualifies Strawson's account as a form of naturalism.

Holding an agent responsible, however, is not necessarily to punish them. It is a separate question, requiring a separate analysis, whether and how we should express our reactive attitudes; there may be conditions on this that go beyond the conditions for holding responsible itself. Suppose that these further conditions are not satisfied. For Vogel, this is for agents to be responsible but blameless or less blameworthy [see Vogel (1993) and Libby $(2010,184)]$. Some (e.g. Levy, 2005) however, treat blame as a reactive attitude in itself, and would use different terminology, e.g., of punishment and reward, to express much the same idea. Similarly, Scanlon distinguishes between blame itself and the expression of blame (Scanlon, 2012, 93), between angry feelings and the infliction of suffering (Scanlon, 2012, 97). For the sake of convenience I will use Vogel's terminology of blame, where one can be responsible without being blameworthy. The important point is that deciding the question of responsibility does not end our consideration of the agent's circumstances, and that we must take care in separating our intuitions about responsibility from our intuitions about blameworthiness. Plausibly, we require a certain standing, or at least take ourselves when acting as judges to require this standing, to blame that we do not require simply to hold responsible or to have (without necessarily expressing) reactive attitudes. This is not necessarily to say that we do not need a standing to have reactive attitudes as well [as argued for instance by Darwall $(2006,11-15)]$, but only that this standing is less demanding. 


\section{Is inability an excuse or an exemption?}

Moody-Adams addresses this question in terms of the distinction between mitigating and exculpatory excuses, the general term "excuse" therefore covering both excuses and exemptions (Moody-Adams, 1994, 293):

$[\mathrm{O}] \mathrm{n}$ some views the thesis provides only a mitigating excuse. According to Slote, for example, the ignorance at stake in the case of ancient Greek slavery was due in part to cultural impediments but also in part to "personal limitations." For Donagan and Wolf, in contrast, the inability thesis provides an exculpatory excuse. Wolf, in particular, believes that the applicability of the thesis actually requires us to withhold blame. But all the views under consideration accept the standard bifurcation of excuses into coercion and nonculpable ignorance, and they then argue that cultural influences can excuse wrongdoing in virtue of their tendency to produce nonculpable ignorance.

Talk of "withholding blame" seems here to mean withholding the reactive attitude. Since Moody-Adams does not believe that the ignorance is non-culpable, perhaps she can afford to be neutral over whether we count ignorance of the kind described by the Inability Thesis as an excuse or an exemption.

Yet there are other places where Moody-Adams seems specifically to be attacking the view that inability is an exemption. At $(1994,292)$ she says: "Against both kinds of views, I contend that the link between culture and agency does not undermine the standard attributions of responsibility for action and hence cannot exempt human beings from responsibility," [my italics] where the views referred to see the agent's capacity for moral knowledge as either limited or incapacitated in certain specific areas by historical and cultural forces outside of the agent's control. We also see Moody-Adams $(1994,306)$ say: “[T]o deny that an unimpaired person has engaged in wrongdoing - even if there are compelling reasons to mitigate our response to the behavior - is to deny the humanity of the person in question." We "deny the humanity of the person in question" when we take an objective attitude towards them, which is to say that we treat their inability as an exemption. It seems to be left open here that inability could be an excuse because a "compelling reason to mitigate our response to the behavior."

Is Moody-Adams (1994, 302-303) claiming that inability might be an excuse but not an exemption when she says that our responses to the behavior should be mitigated in so far as we should respond in a more forgiving way when we believe such an inability to be 
present? One wonders whether Isaacs is being very charitable to Moody-Adams when Isaacs summarizes Moody-Adams's paper as the claim that inability cannot mitigate, since there seems to be a basic agreement in principle between Moody-Adams and Isaacs that our responses to this kind of wrongdoing should take inability into account, Isaacs preferring a dialogue to Moody-Adams's attitude of the "forgiving moralist."

How, then, does this square with what Moody-Adams says near the beginning of the paper where she strongly implies that inability is not an excuse? I think that when MoodyAdams talks about mitigated responses to wrongdoing she is talking about how our reactive attitudes should be expressed rather than what reactive attitudes it is appropriate to have. It is appropriate to hold the wrongdoer responsible, which in the terminology she uses is to say that it is appropriate to blame them, but inability is a mitigation in the further sense of being a condition on our response. Just because it might not be "reasonable to expect" an agent to know better does not necessarily mean that we should not hold him responsible (Libby, 2010, 184); we should hold him responsible while still, perhaps, mitigating his blame, or expressing that blame in a more understanding and compassionate way.

A common intuition in cases of inability is that a severe response would be hypocritical, and this tends to slide into the thought that holding the agent responsible would be likewise hypocritical. I am not actually convinced that avoiding hypocrisy is a condition of blame, as I will argue later, but even if we concede this, we do not similarly need to concede that it is a condition on responsibility, that the reactive attitude itself is inappropriately held or permissibly withheld just because we think that we would not have behaved any differently.

I think that it is the same kind of intuition that is invoked in the following kind of case: suppose that someone leaves their car parked on a hill. The car has faulty brakes, the car slides down the hill, and causes an accident. The owner of the car was ignorant with regards to the defectiveness on the brakes, and though in many cases such ignorance would be culpable, let us suppose that in this case it is not, that the owner takes the amount of care that the law and society expects of them. Is the owner responsible? I think that he plausibly is, at least in some cases; perhaps society does not expect as much as it should, perhaps the agent would normally hold himself to a higher standard than society strictly demands and the accident is a direct result of his back-sliding. Yet I can imagine a judge, faced with this case, might reason in the following kind of way: "There but by the grace of God go I. It would be unjust to punish him unduly (or even, perhaps, to hold him responsible at all) when I would not have behaved any differently in that situation, and nor would most people."

Libby reports that this was a common intuition of several students faced with cases of 
inability:

If I think that it is likely that I would have owned slaves had I been born into the American slave-owning South, then it is not appropriate for me to say that slaveowners were blameworthy. Likewise, if I think that I would have followed the orders of the SS, then it is not appropriate for me to blame those who did. (Libby, 2010, $10)$.

However, she considers this intuition mistaken:

Perhaps she was worried that she would be labeled a hypocrite for pointing out the moral mistakes of others in light of the fact that she herself had surely committed her own mistakes. . . . [T] his charge of hypocrisy . . . would be fallacious. The fact that Emmy has failed to perform all and only morally permissible actions is not logically relevant to her arguments attempting to establish that some other individual has done something morally impermissible. (Libby, 2010, 7-8).

It is not clear whether Libby finds this intuition as equally mistaken and tu quoque with regards to punishment/blame. Vogel $(1993,135-36)$ invokes precisely the same "There but by the grace of God . .." intuition, though he sees it is an appropriate mitigation of blame (at least in cases where the upbringing of the agent in question was one of deprivation) though not a condition of responsibility as such.

Such a response need not deny that the owner was responsible, but the judge tasked with holding the owner responsible may fail to do so or otherwise moderate his response. Inability could be a reason in the same way: not an exemption or excuse, or a reason why the moral community as a whole should not hold the agent responsible, but rather a personal reason that conflicts with, and sometimes defeats, the community's reasons for holding the agent responsible for the official tasked with instituting a response. In short, Moody-Adams can be understood as saying that mitigating our response need not and does not involve an undermining of or change to our responsibility-attribution. We can look back from our advanced viewpoint on Greek slavery and view slave-owners as morally responsible for their practices, while conceding that if we had been brought up in that culture and in those conditions we would have done the same and would have found the moral knowledge that is lacking just as difficult to come by. This amounts to an error theory for our (as it happens, mistaken) feelings about the appropriateness of holding responsible in cases of inability: our intuitions about responsibility are conflated with our intuitions about blameworthiness and our feelings about whether we are entitled to, and have the standing to, express blame.

This can be illustrated also in the converse case where, despite the judge considering that he himself would not have behaved differently, he blames the agent even so. The agent may respond something like "What right do you have to judge me?" when backed by things like "You are just as bad yourself!", "You would have done the same," "You have done the 
same yourself," and, more tersely, "You hypocrite!" This seems to generate conflicting intuitions, on one side such a response (exemplified by Libby) as "That's irrelevant! Do as I say and not as I do!" to "Yes, you're right; it is self-righteous of me to hold you responsible for doing what I have done/would do myself."

But this does not undermine the appropriateness of the responsibility-attribution, but only the force of the blame. Neither interlocutor is disputing the facts of the case - they may well agree that the agent is blameworthy. Where, then, is the defect in blaming him? How are we to understand the agent's complaint? There are blamings or at least sanctions that do not have the kind of moral force indicated by reactive attitudes, such as when their warrant is given entirely by social regulation. The same sanction can be seen as the externalization of either a reactive attitude or an objective attitude, and may be warranted as the latter but not the former. Thus, "Who are you to judge me" could be glossed as "I agree that I have done something blameworthy and perhaps I should be incarcerated in order to protect society. Also, I do not dispute your legal authority to have me incarcerated. But I do not accept your moral condemnation or your moral authority." By this he asks for an objective attitude and an instrumentally-warranted sanction; it is only to these that the other is entitled, according to the complaint. Perhaps he might also allow that the other is entitled to moral evaluation, but not to blame with the kind of force that we typically give it, because to be entitled to that force according to the intuition being pumped - the blamer must be consistent, he most hold himself to the same demands he makes of others. What is more, it seems that the authority himself might agree, and (rightly or wrongly) foreswear blame and even the responsibilityattribution in this case because believing it is inappropriate for him personally to do so, though appropriate for the moral community as such.

Let us go back to Benson's way of formulating the Inability Thesis for a moment. $\mathrm{He}$ is talking about whether it is reasonable to hold somebody to an expectation that in that person's own culture is not an expectation and would in fact be in conflict with that culture's expectations. If this is a question of whether it is reasonable for an individual to hold somebody to an expectation then this might be because the individual would be being hypocritical, might be applying the double-standard that Pleasants mentions. But this question is not a question about responsibility as such, as Moody-Adams's critics seem to suppose; Benson's way of putting the matter tends to lump together (as people themselves often tend to lump together) the two different kinds of intuitions.

By the same token, I disagree with Pleasants' claim that we are not to be held responsible for acts whose moral wrongness are the subject of serious disagreement. Suppose 
that after a period of serious disagreement one side wins and the other comes to realize that, without knowing it, they have been acting inconsistently with their own principles. It seems to me that they are responsible for the acts they performed in their state of moral ignorance and it is appropriate for them to feel guilty and to desire to make restitution if they can, though our response towards them - the force of the blame - should be mitigated; it is because we foreswear blame on the grounds that blame seems hypocritical in such a case that accounts for the plausibility of Pleasants's claim. Once we have agreed to a moral principle, we have agreed to all of its instances, we have agreed that it applies in any relevantly similar circumstances, even those in the past before we agreed to or correctly perceived the principle. So, assuming that it is inappropriate to hold someone else to an expectation or demand that one would not hold oneself to in the same circumstances, it is still not obvious that this way of putting the matter (defended in one way or another by all of Moody-Adams's critics) undermines the responsibility-attribution itself; these criticisms fail to distinguish between mitigating the responsibility-attribution - that is to say, being an excuse - and mitigating the force and/or warrant of the blame.

But is hypocrisy a condition of blame? Is it actually inappropriate to hold someone else to an expectation or demand that one would not hold oneself to in the same circumstances? Does a blamer need to be consistent and, if so, why? Is hypocritical blame non-blame? Wallace's answer is, briefly, that when we blame hypocritically we are implicitly taking ourselves to be of a different moral standing to the one we blame, and by doing so fail to respect our equality as persons (Wallace, 2010). I find this less than obvious and, in fact, I do not think that a blamer must be consistent over time. In fact, I believe that when I blame an agent for an action I implicitly blame all relevantly similar agents performing relevantly similar actions. If I myself have performed such actions then I fall within the scope of my own blame, and I may indeed realise this and deeply regret my past transgressions and see them for what they were and see the excuses and justifications I may have appealed to at the time to be the self-deceptions they were. The 'inconsistency' involved here seems to be nothing more or less than conscience. Thus, there is no moral fault in hypocritical blame - it is often the first step on the road to moral realisation and non-hypocritical blame. This is not to say that being hypocritical is not a morally reprehensible quality in and of itself, but being hypocritical must be understood here as blaming others for acts relevantly similar to an act that one has performed oneself without accepting, or at least being prepared to accept when one's attention is drawn towards it, one's guilt for that act. But, as was mentioned before, we 
should not conclude from his responsibility for this avoidable epistemic failure that there need be anything defective in the blame itself or unwarranted in giving the blame its usual force, especially since this force ultimately comes from the moral community itself.

\section{Is inability mitigating because of an epistemic failure?}

Despite defending Moody-Adams in this way, I think she puts rather too much store in the notion of affected ignorance. I think Benson is right to say that it is implausible that in all such cases the agents involved simply "affect" ignorance. There is, however, another point in Moody-Adams's paper that neither she nor her critics really discuss that is not related to affected ignorance, or in fact to ignorance at all; I will argue that it is this that actually underlies or at least should underlie our responsibility-attributions in these kinds of cases. This is her claim that by behaving in certain ways, by complying with the expectations and behaviours attendant on the morally repugnant practice, agents accept and perpetuate that practice. Benson stresses that cultures need not be literally agents or causes, but that they nonetheless play roles in explaining the behaviour in question, as Moody-Adams concedes. He doesn't actually say so, but this may be enough to say that the culture itself is responsible. But normally when the culture is responsible the members of the culture are also responsible (at least to some degree), since those cultural influences are in the end reducible to and/or supervene on the behaviours and practices in question - a practice is "in practice" an aggregate of individual actions. This may be so even if, like Moody-Adams, we are reluctant to count cultures as appropriate possessors of moral predicates like responsibility.

If so, I think that it does not matter what moral knowledge the individual has. Suppose that a Greek slave-owner hears some of the arguments of the dissident critics and finds them at least partially persuasive. Is he then obliged to give up his practices? Perhaps he is weakwilled and does not want to give up a practice that benefits him personally, but perhaps he is simply modest and does not want to put his own judgment up against those of his peers. If the intellectuals and law-makers come to the conclusion that slavery is in fact a morally wrong practice then he is quite prepared to give it up, but while there remains serious disagreement about its wrongness he will stick to what his culture accepts. In doing so, he also accepts the practice, whatever his personal attitudes and feelings are about the matter. Nor need this be the wrong thing to do - often we are obliged as members of a society or as part of a collective to accept attitudes and beliefs that we do not in fact share, such as when a member of a political party puts the "party line," or the political opinions of their constituents, ahead of 
what they may as individuals feel about a certain political issue. In such a case the individual is as responsible as the collective itself is responsible - if the collective is responsible, then the individual is responsible, and if not, not. The moral knowledge that the individual has in this case does not, in fact, alter the case one way or the other. What the individual knows and what he accepts as a member of the collective are two different things.

I take a kind of "entity realist" view on the autonomy of collectives. If by appeal to cultural influences you can predict mass behaviour and devise experiments that reproduce that behaviour then culture is a real "thing" and can appropriately be attributed with the kind of predicates and even causal powers that are typically reserved for individual agents. By saying that it has this kind of autonomy I am not making any claims about the reducibility or otherwise of the collective; I think it likely that the attitudes that can be attributed to the collective do supervene on the attitudes of its members, but not necessarily the same attitudes with the same representational contents. This applies to reactive attitudes as well as cognitive attitudes. As mentioned above, the moral beliefs of the culture - its value-system - do not require moral beliefs with the same content on the part of individuals, but only their passive acceptance, in this case by continuing the practice. Forrest $(2006,150-51)$ makes a similar point with regards to the self-reactive attitudes guilt and shame; participation in itself is enough to make participants appropriate objects of their own shame by virtue of the guilt for collective wrongdoing they share as members of the collective. By doing this, it is fair to say, as Moody-Adams charges, that they are perpetuating the morally skewed values of their culture and are responsible. Ignorance has nothing to do with it.

Benson (2001, 616-17) argues against the view that simply by perpetuating the culture people are responsible. He points that our moral ignorance may be due to other people's choices to perpetuate the culture rather than our own, and even our own choices may be made under circumstances where they are less than fully voluntary, or chosen under descriptions having nothing to do with cultural norms, or for some other responsibility-undermining reason. I would argue that this makes no difference. I will present a minimal account of joint action and show that our conceptions of what we are doing when we engage in such collective wrongdoing has little to do with it. Because it seems the least demanding I will use the account of Kutz (2000) in which joint actions involve what Kutz calls participatory intentions and a shared goal.

A participatory intention has an individual role and a collective end. The relation of the individual act to the collective end might be expressive of one's membership of a 
collective, like wearing a business suit, or normative, complying with standards within the collective. It is the agent's conception of this relation that makes her intentions participatory it must be seen as instrumental to the collective action and as generating some form of obligation through either formal rules or social expectations (Kutz, 2000, 10-13), that is to say, it leads to a normative commitment. These intentions are said to be strategically responsive when they are sensitive to what the agent thinks other agents are going to do.

Shared goals do not require mutual expectation and responsiveness but only an extensional overlap of the acts performed with participatory intentions. Consider the joint action of saving a picnic. It starts to rain, and quite spontaneously one person grabs the food and the other grabs the crockery and cutlery:

\begin{abstract}
So joint action as such requires neither positive belief about others' intentions nor dispositions of responsiveness, since we can conceive of genuinely joint, if simple, forms of collective action in their absence so long as agents nonetheless act with participatory intentions. Only one further general condition seems to be required as part of the very concept of joint action: a condition of extensional overlap. It must be the same joint enterprise in which agents intentionally participate [...].

[...] Agents' intentions overlap - they share goals - when the collective end component of their participatory intentions refers to the same activity or outcome and when there is a non-empty intersection of the states of affairs satisfying those collective ends. (Kutz, 2000, 20).
\end{abstract}

Here both agents act with the same end in mind, viz., saving the picnic, but this is not necessary since the overlap need only be extensional; the participatory intentions need only refer to the same activity. Kutz gives an example where each agent conceives their end under different descriptions. You are going to a friend's house for a quiet dinner and I am going there for a surprise party thrown for you. Our intentions overlap under the description of going to a friend's house, which satisfies both of our ends, so we have this as our shared goal. Just as an action can be intentional under one description and not under another, so also can it be jointly intentional under one description and not under another (Kutz, 2000, 21).

Let us apply this to the Greek slave-owner. Suppose the slave-owner is beating his slave and that this is a socially accepted practice. All who engage in this practice share goals under some description, and quite possibly a description that makes them morally neutral or even admirable, e.g., enjoying the rewards of excellence in the martial virtues. By beating the slave the slave-owner has a participatory intention with this as his collective end, his individual act is related to the collective end in a normative way by complying with the normative standards of the society, and because of these normative standards and social expectations he actually has a normative commitment to act in this way.

This is so irrespective of whether the slave-owner sees his behaviour under the description "perpetuating the values of the society." Very likely this description never occurs 
to him and so the correlative act is not something that he does intentionally; the goal of perpetuating the practice is shared, even if nobody conceives their collective end under this description, since only an extensional overlap is required. The fact that they are not chosen under this description, as Benson charges, is not relevant. Again, I think that the focus on moral ignorance is a distraction. Not only are individual agents responsible for the acts they individually perform as parts of joint actions, they share responsibility for the acts that others perform as well. Even if we are morally ignorant because of other's choices to perpetuate the culture, as Benson also charges, this does not mean that we are not also responsible. All who engage in the practice are responsible for the individual acts that are, at the end of the day, all that the practice amounts to.

This is a slightly odd case of joint action, to be sure - it is not as if all members of the society take it in turns to beat the slave, or have to contribute something to the beating such that the beating could not have occurred without their co-operation. Described only as a beating, the act is not jointly intentional, though it is intentional from the agent's own point of view. Described as part of a practice, however, the act is jointly intentional, though it is conceivably not intentional from the agent's own point of view since he does not have an intention whose content is "perpetuate the practice." The social fact that makes the beating part of the practice of slavery is something to which every member of society contributes to making true. So, this does count as a joint action on Kutz's view, and this seems to be implied when Kutz says that conceiving the relation between the individual act and the collective end can be the normative one of conforming to the standards of the society.

So, if by perpetuating the practice the slave-owner is culpable for the morally wrong acts deemed acceptable by the practice, then the slave-owner is culpable full stop, and it does not matter whether the slave-owner conceives his act in those terms or whether the act is intentional under that description; all that matters is a participatory intention. That intention should, I would say in these cases, be strategically responsive to cultural changes, but is by no means obliged to bring those changes about. On the contrary, the obligation is always in favour of the status quo. Since this is so - since it is a joint action - responsibility must also be joint. We can say that the collective is responsible as well as saying that the slave-owner is responsible.

However, I think that there is a problem that has so far been left aside with regard to attributing responsibility to a collective for its wrongdoing. To be responsible for something, one must be responsible to something, and only what one is responsible to can hold one 
responsible (Darwall, 2006, 68). What is the Greek slave-owner responsible to? Greek society, or perhaps a certain class within Greek society, has the standing and authority to hold him responsible. Would someone who was a member of that society or class, perhaps even a dissident member of that society or class, hold the slave-owner responsible? It seems not: for the normal member of society there is no case to answer because, as Isaacs $(1997,675)$ points out, there is often no recognition of a moral issue to begin with, and, in a sense, no ill-will on the part of the agent, and for the dissident member of society (supposing that such a dissident is somehow in a position to hold responsible in the first place) the moral ignorance seems non-culpable and to fall under the Strawsonian excuse "He didn't realise." It would therefore be inappropriate for anyone who actually could hold the agent responsible to do so. When we find Greek society and Greek slave-ownership morally responsible we do so by imposing our own value-system as an external criterion, and this is against at least the spirit of Strawson's account for whom all the reasons that regulate our reactive attitudes are internal to the framework that the attitudes themselves and their embedded standard of appropriateness provides. That we cannot hold Greek society responsible is not just because we would deem it hypocritical to do so, or out of a (misplaced) desire not to seem smug or self-righteous or to avoid acknowledging the banality of wrongdoing (Moody-Adams, 1994, 298-303) - it is a conceptual problem. For the intra-cultural case, Pleasants seems to be right after all, and what we have to consider is whether some members of the culture should be able to see a particular moral issue in the same way as other members.

What about the inter-cultural case? Often one collective is responsible to another collective: tenure committees to universities, departments to sub-divisions, sub-divisions to divisions. Where this is so, the dominated collective can be held responsible by the dominating collective. But this is not generally so in the kinds of cases being discussed.

What is, however, quite frequently the case is that an individual is a member of more than one collective and there is a collision between what those collectives endorse in a particular situation. Tunick $(2009,395-96)$ gives a couple of examples. The first concerns some Moslem refugees. The father arranged the marriage of his two daughters, one thirteen and one fourteen years of age, to two older Moslem men, who consequent to consummating the marriage were charged with sexual assault of their 'wives.' This was all in accordance to Moslem custom, and it was claimed that they did not know that this was illegal. The second concerned a Japanese woman who attempted a parent-child suicide but, succeeding only in the murder part of the plan and surviving the suicide attempt, found herself charged with murder. Again, this parent-child suicide, committed from shame that her husband supported a 
mistress, was in accordance to Japanese custom. How should the fact that these acts were not wrong from the agent's own point of view, or that they were morally ignorant of the wrongness, affect the matter?

Here, it makes little sense to blame Moslem or Japanese society or feel indignant towards them, since those societies are not responsible to the Western societies in which those cases occurred. Earlier I said that because the society or culture was morally responsible and because by behaving in the way the agents did they were perpetuating that culture or those cultural practices, they also were responsible. But I am now saying that the society or culture is often not responsible for those practices because not responsible to those who hold those practices to be morally wrong. The moral wrongness of those acts is not affected, but arguably moral responsibility is. Can the agent still be responsible by virtue of perpetuating those morally wrong cultural practices, even though the culture itself cannot?

In principle, I think the agent can still be responsible. Note that by living in a foreign society one is not only bound by their laws (as the judges in these cases rightly pointed out) but they also accept as members of that society the principles underlying those laws, even if they do not actually as individuals believe in those principles; I noted above that moral ignorance was not really the issue because what counts in the collective case is only (often passive) acceptance and not what the individual believes or knows. So, the Moslem men and Japanese woman are responsible to the society that they live in and violate the expectations of that society, even if in doing so they conform to the expectations of their own culture, and even if as individuals they believe in the practices of their own culture and only passively accept the practices of the culture in which they live. I think that the best way of putting this is to say that there is a consideration (namely, that it is not responsible to the foreign culture in question) that defeats the collective's responsibility but (in cases where the individual is responsible to the foreign culture in question) not the individual's responsibility. The individual can be responsible, and responsible because they perpetuate a morally wrong cultural practice, even though the culture itself is not responsible (because it cannot be held responsible) for the morally wrong cultural practice. This does not prevent us from taking the view, mentioned earlier, that we should mitigate our response on the grounds that social pressures would have made going against their own embedded cultural beliefs as difficult for the agents in question as going against our own embedded cultural beliefs is difficult for us. In fact, the judges did give lighter sentences than would normally be given for the crimes committed. 
However, I do not discount the possibility that inability might be offered as an excuse or exemption. Consider the excuses "He didn't realise" or "They gave me no choice," or the exemption "His mind has been systematically perverted (with regard to the practice in question)." There seems to be some leeway for what a particular moral community or culture allows as grounds for these claims. For a child "They double-dared me" might serve as grounds for "They gave me no choice," while extremely strict societies might need something extremely rigorous, for instance a strict Catholic might argue that however terrible are the things that you would have let happen by not performing a morally wrong act, nonetheless you should not have performed the act and are morally responsible and even blameworthy for doing so.

Allowing or disallowing cultural influences to serve as responsibility-undermining reasons is itself an embedded cultural practice and expresses the value-system of the society that the agent is responsible to. The same might be said for hypocritical blame, which might be more acceptable in some societies than others. So, the agent might be responsible or might not, and if she is not, we might mitigate our response, or we might not. I do not think that there is an a priori answer to be found for this question just by analysing the concepts involved. What we can say, I think with some degree of certainty, is that inability does not exclude the agent from moral appraisal, that the agent is vulnerable to moral evaluation, which it is then the task of the substantive moral principles endorsed by the judging moral community to determine. This amount of relativism is unavoidable unless we help ourselves to external criteria; this is questionable for responsibility-attributions, and if the relation between being responsible and holding responsible is as close as the reactive attitudes theory supposes, it is equally questionable for responsibility itself. Conceptual analysis of the concept of responsibility will not give you a fixed set of conditions under which agents are or are not responsible, but naturalistic description of our habits of holding responsible will give us a kind of dialogue-model into which all such conditions must fit. This will tell us what responsibility-attribution we ought to make as judges, even if we deny that it will tell us whether or not the agent is actually responsible. But it is the former, I would say, that should really interest us more than the latter, for it is the former that will provide us guidance in our own moral practices of blame and punishment.

As a final point, we have said that agents can be responsible without the collective being responsible. Is the converse true? Can there be cases where the collective is responsible but no member of the collective is responsible? If there are, of course, this is even more reason to take the collective as having autonomy. Such cases may occur when, perhaps, the 
person who is in the position to do something on behalf of a collective fails to do so because of, for instance, a conflict between their duty to the collective and some more personal duty, such as caring for a sick child. Personally I think that this excuses the individual but not the collective, since the collective has no such personal duty. I also mentioned above that the individual may take it as a personal duty not to be hypocritical or two-faced, in which case his failure to blame when blame seems appropriate might itself be excusable. It does not matter for my purposes here whether this is right or wrong, for the case being considered is not among those cases debated. Although it is possible in principle to not hold the individual responsible, this does not seem to apply in the kind of case we are discussing here.

Suppose that a tenure committee has a faulty procedure for granting tenure. The tenure committee is responsible to the university. The university may hold the committee responsible for that procedure and for the morally wrong decisions that may have issued from it. I have argued that the members of the tenure committee are equally morally responsible for that wrongdoing, whether they are able to see the wrongness of the procedure or not, since they follow it anyway and may be normatively bound to do so (if the situation is anything like that which Kutz describes). But suppose that each member of the committee, through no culpable fault of their own, has not been able to give an application for tenure, or perhaps the procedure itself, adequate attention. This seems to excuse the members of the tenure committee, not, I think, because the members of the committee are non-culpably ignorant of whether the application is a good one or the procedure a fair one, or even because moral reflection on the procedure's fairness would be supererogatory (which is not itself responsibility-undermining), but because in the strained circumstances of caring for a sick child, for example, the duty of caring for the child amounts to a duty to not morally reflect on the procedure's fairness, since moral reflection on the procedure and care for the sick child cannot both be fulfilled in this instance. It is not that I think moral reflection is in this case impermissible, but that it cannot be done without incurring fault elsewhere that may reasonably be supposed to take precedence for the agent. Though this remains controversial, I believe that these excuses would not excuse the committee itself. In result, the university may hold the committee responsible while accepting all the individuals' excuses. Cultural influence does not seem to be the kind of personal reason in question here. 


\section{Conclusion}

Sometimes we feel that it would be inappropriate to hold some agent responsible. How strongly do these feelings count as evidence that, in fact, these agents are not responsible? Unless we are to abandon any attempt to accommodate our theories to our moral intuitions, they must count for at least something, but there is more than one way that we might interpret the evidence.

Consider Bob who disapproves of the way Ted treats Alice. It might seem inappropriate to Bob to hold Ted responsible, on the grounds that it is not really any of Bob's business and that Bob is not really in the kind of relationship to Ted and Alice to be in a position to hold Ted responsible. Let us suppose, for the sake of argument, that in fact it is inappropriate. Smith (2007) uses this kind of case to argue that being responsible cannot be analysed purely in terms of holding responsible in the way some versions of the reactive attitudes theory suppose, for the agent is morally responsible, she says, even though they cannot appropriately be held responsible. Alternatively, we might explain this by saying that this is evidence only that Bob does not have the standing to blame (in Vogel's sense), while the responsibility-attribution itself is appropriate. I am not saying who is right or wrong here, but only that there always seems to be an alternative way to explain away the evidence of our moral intuitions.

But let us suppose now that the agent is not responsible, thereby re-establishing the connection between being responsible and being held responsible. There is a temptation now to treat the fact that we do not hold the agent responsible and feel it would be inappropriate to do so as evidence that here is a case of non-culpable moral ignorance, and in some cases an inability: perhaps in the culture Ted and Alice belong to the woman is considered to be inferior to the man and the kind of behaviour Bob finds unacceptable is acceptable in that culture. Let us even suppose that this is in fact a case of moral ignorance. But, just because we do not hold the agent responsible, or feel that doing so would be inappropriate, is it safe to assume that the moral ignorance in question is non-culpable?

Moody-Adams (1994) offers another hypothesis to fit the same evidence that the Inability Thesis accounts for, namely that Ted is "affecting" ignorance and is therefore culpable. For Moody-Adams it would not be inappropriate to hold the agent responsible, and the feeling that it is inappropriate has other causes: reluctance to appear smug, reluctance to acknowledge the banality of wrongdoing, and, I would add, reluctance to appear hypocritical. It is not that inability is completely irrelevant, since we are right to respond differently to 
cases of inability than other cases, and plausibly this is what we are doing when we foreswear blame in order to avoid being hypocritical, but inability does not of necessity, that is to say, in principle, make the responsibility-attribution itself less appropriate, or make the agent any less morally responsible; we must not confuse our intuitions about responsibility with our intuitions about blame. Or perhaps Wallace (2010) is right and hypocrisy really does make holding the agent responsible inappropriate, and the agent is not responsible in these cases.

There is a sense, however, in which hypocrisy plays a part suggested by but not really developed in Pleasants' paper. One way of putting the point is to consider the moral reasoning involved on the model of a dialogue. The dialogue is between the agent and a moral community that the agent is responsible to. All such dialogues follow the framework of excuses and exemptions that Strawson sets out, but (against Strawson) I would say that different communities may find different things to be appropriate grounds for the excuses and exemptions. The Japanese woman's reasons for killing her child will be good to a Japanese community but not to a Western community. However, the subtly but importantly different claim that these reasons would be satisfactory in the Japanese culture in which she was raised and that this amounted to an inability, may or may not be considered appropriate grounds for being excused or exempted. If it is not, we may still explain the feeling that it might seem inappropriate on the grounds that we should respond differently (everyone, I think, concedes at least this much). But what the community cannot do is impose its criteria on those who are not responsible to it; such agents are simply outside of any possibility of meaningful dialogue, and hence outside the standards of appropriateness embodied in the dialogue. This is why serious disagreement within the dialogue can only be resolved by appeal to a principle that all parties to the dialogue share, often by using analogical arguments designed to illuminate the proper scope of said principle, as Pleasants says.

To be responsible to a community is at least partly to share goals with other members of the community. However, this condition is minimal, since our goals need not be shared by our having as the content of some representational state some special description of the goal, but only that there is a state of affairs that matches the different descriptions we may have. In fact, I do not believe that there needs to be a representational state whose content is such a description at all, or at least not a cognitive state; an acceptance of the goal (i.e., a practical attitude that has some description of the goal as its content), or maybe just behaviour in accordance with that goal, is enough to be a member of the community and to be responsible to that community. It is because she is in this way a member of the Japanese moral 
community that the Japanese woman is responsible for the wrongdoing involved in the cultural practice she perpetuates, and because she is in this way a member also of the Western moral community that it is appropriate to find her responsible, despite the fact that the Japanese community itself is not responsible to the Western community and hence cannot be appropriately held responsible. It doesn't matter here which culture's value-system she considers better or is more committed to, she participates in both, even if her participation is active in one and only passive in another. This makes her addressable in the dialogue and makes her an apt object for moral responsibility.

This means that it matters far less than the Inability Thesis supposes whether the agent is morally ignorant. It also means that responsibility is relative to the community doing the judging, for she is not responsible (or less responsible) relative to the Japanese moral community that she is also responsible to (not because of her 'inability,' since here it would not be seen as an inability but as correct moral perception, but because the values themselves provide whatever moral justification she can be required to give), with the unfortunate (for her) consequence that she is responsible and not responsible for the same thing and at the same time, and if she had not gone through with the practice she would have been responsible relative to the Japanese moral community and not the Western moral community. These are different dialogues with different dialogue partners.

There is a difference, then, in the conditions of responsibility for individual acts and acts that belong to cultural practices. For individual acts it is plausible that the agent must understand what he is doing, that he must do it intentionally, and perhaps even that he be autonomous with respect to it, which is to say that it reflects values he endorses. I am not sure that any of these conditions are true when the acts belong to cultural practices. Or perhaps what we should say is that these are conditions that the collective must satisfy. Remember that we can attribute attitudes to the collective, both intentions and beliefs, without attributing attitudes with the same content to any members of the collective; collectives who choose to resolve discursive dilemmas by collectivising reason are a good example of this phenomenon. Plausibly, we can apply the same epistemic conditions to the collective on the basis of attitudes attributable to the collective, probably on the further basis of the participatory intentions, shared goals, and acceptances of the members of that collective.

There is a further difference we should make, this time between acts that belong to cultural practices and acts that simply arise out of cultural circumstances. The tendency in the discussions is to consider the case of the Greek slave-owner and another kind of culturally influenced case together. This other kind of case is exemplified by the child who has become 
an evil adult because moulded by adverse social conditions over which they had no control. This kind of agent is not participating in an accepted cultural practice and does not do what he does because part of a collective. On my view these are simply two entirely different things and require separate analyses. 


\section{References bibliography:}

Benson, Paul. (2001). Culture and responsibility: a reply to Moody-Adams. The Journal of Philosophy, 32(4), pp. 610-620

Darwall, Stephen. (2006). The second-person standpoint: morality, respect, and accountability. Cambridge, Massachusetts and London, England: Harvard University Press

Forrest, Peter. (2006). Collective guilt; individual shame. Midwest Studies in Philosophy, $X X X$, pp. 145-153

Isaacs, Tracy. (1997). Cultural context and moral responsibility. Ethics, 107(4), pp. 670-684

Kutz, Christopher. (2000). Acting together. Philosophy and Phenomenological Research, 61 (1), pp.1-31

Levy, Neil. (2005). The good, the bad and the blameworthy. Journal of Ethics \& Social Philosophy, 1(2), pp. 2-16

Libby, Heather Elizabeth. (2010). Evil perpetrators or cultural victims? An examination of the relation between cultural membership and moral responsibility. $\mathrm{PhD}$ diss., University of Iowa. http://ir.uiowa.edu/etd/846

Moody-Adams, Michele. (1994). Culture, responsibility and affected ignorance. Ethics, 104(2), pp. 291-309

Pleasants, Nigel. (2008). Institutional wrongdoing and moral perception. Journal of Social Philosophy, 39(1), pp. 96-115

Scanlon, Thomas. (2012). Interpreting blame. In D. Justin Coates and Neal A. Tognazzini (eds.) Blame: its nature and norms. New York: Oxford University Press

Smith, Angela M. (2007). Being and holding responsible. The Journal of Ethics, 11, pp.465484

Strawson, P. F. (2008). Freedom and resentment. In Freedom and resentment and other essays. New York: Routledge

Tunick, Mark, (2009). 'Can inability excuse crime?' Evaluating the inability thesis. In Punishment \& Society, 6(4), pp. 395-409

Vogel, Lawrence. (1993). Understanding and blaming: problems in the attribution of moral responsibility. Philosophy and Phenomenological Research, 53(1), pp. 129-142

Wallace, R. Jay. (2010). Hypocrisy, moral address, and the equal standing of persons. Philosophy \& Public Affairs, 38(4), pp. 307-341 